\title{
Global Methodology to Integrate Innovative Models for Electric Motors in Complete Vehicle Simulators
}

\author{
A. Abdelli and F. Le Berr \\ IFP Energies nouvelles, 1-4 avenue de Bois-Préau, 92852 Rueil-Malmaison Cedex - France \\ e-mail: abdenour.abdelli@ifpenergiesnouvelles.fr - fabrice.le-berr@ifpenergiesnouvelles.fr \\ * Corresponding author
}

\begin{abstract}
Résumé - Méthodologie générale d'intégration de modèles innovants de moteurs électriques dans des simulateurs véhicules complets - Comment réduire les émissions moyennes de $\mathrm{CO}_{2}$ des véhicules particuliers à $120 \mathrm{~g} / \mathrm{km}$ en 2012 et $95 \mathrm{~g} / \mathrm{km}$ en 2020 comme le prévoit l'accord conclu entre la Commission Européenne et les constructeurs européens ? Cette question à réponses multiples préoccupe à l'heure actuelle l'ensemble du monde automobile. L'électrification des véhicules semble être une des solutions les plus pertinentes, ce qui pousse les constructeurs à envisager des véhicules hybrides de plus en plus innovants. Cette solution, théoriquement très intéressante, complexifie encore un peu plus les groupes moto-propulseurs des véhicules, ce qui nécessite l'utilisation d'outils de simulation adéquats pour réduire les coûts et les durées de développement. La simulation système, outil déjà primordial dans le processus de développement des moteurs à combustion interne, devient alors incontournable. Pour étudier ce type d'architectures hybrides complexes, et à l'instar des modèles physiques développés pour le moteur à combustion interne, la simulation système doit se doter de modèles prédictifs comparables pour les machines électriques. Dès leurs spécifications, ces modèles doivent intégrer certaines contraintes très exigeantes sur les temps de simulation, contrainte garantissant par la suite une plus large utilisation des simulateurs, notamment pour le développement et la validation de stratégies de contrôle. L'objectif de ce papier est donc de présenter une méthodologie générale de développement de modèles de machines électriques, modèles ayant pour objectif final d'être intégrés dans un simulateur véhicule complet. Cette méthodologie met en scène différents types de modélisations (modèles éléments finis, modèles de caractérisation, modèle de simulation) permettant un compromis temps de calcul - précision adéquat. Cette méthodologie a été déployée avec succès pour la modélisation d'un moteur synchrone à aimants permanents. À l'issue du processus de modélisation, ce dernier a été intégré dans un simulateur complet de véhicule hybride, garantissant son bon fonctionnement et sa bonne intégration dans le processus global de conception d'un nouveau prototype.
\end{abstract}

\footnotetext{
Abstract - Global Methodology to Integrate Innovative Models for Electric Motors in Complete Vehicle Simulators - By what means the greenhouse gas emissions of passenger cars can be reduced to $120 \mathrm{~g} / \mathrm{km}$ in 2012 and $95 \mathrm{~g} / \mathrm{km}$ in 2020 as the European Commission and the automotive manufacturers are stated? This question with multi answers preoccupies at the moment the whole automobile world. One of the most promising solutions which receive attention is the electrification of the vehicle. It is this idea that has prompted the automobile manufacturers to envisage increasingly innovative hybrid vehicles. However, this theoretically interesting solution makes more complex the powertrain, which requires the use of simulation tools in order to reduce the cost and the time of system development. System simulation, which is already a crucial tool for the design process of internal combustion engines, becomes indispensable in the development of the Hybrid Electric Vehicle (HEV). To study the complex structures of HEV, following the example of the physical models developed for the internal combustion
} 
engine, system simulation has to provide itself of the same predictive models for electric machines. From their specifications, these models have to take into account the strict constraint on the time simulation. This constraint guarantees the wide use of simulators, notably to help the development and the validation of control strategies. This paper aims to present a global methodology to develop innovative models of electrical machines. The final objective of these models is to be integrated in a global vehicle simulator. This methodology includes several types of models and tools, as Finite Elements Models (FEM), characterization and simulating models. This methodology was applied successfully to model an internal permanent magnet synchronous motors. At the end of the modelling process of the electric motor, the latter has been integrated in a complete global hybrid vehicle. This guarantees the good operation and integration in the global process of a new vehicle concept.

\section{ABBREVIATIONS}

$\begin{array}{ll}\text { EM } & \text { Electric Motor } \\ \text { FE } & \text { Finite Element } \\ \text { FEA } & \text { Finite Element Analysis } \\ \text { FEM } & \text { Finite Element Model } \\ \text { HEV } & \text { Hybrid Electric Vehicle } \\ \text { ICE } & \text { Internal Combustion Engine } \\ \text { IPM } & \text { Interior Permanent Magnet } \\ \text { MTPA } & \text { Maximum Torque Per Ampere } \\ \text { PMSM } & \text { Permanent Magnet Synchronous Motor } \\ \text { V-IPMSM } & \text { Interior Permanent Magnet Synchronous Motor } \\ & \text { with V-shape magnet }\end{array}$

\section{INTRODUCTION}

In today's industrial world, one question always comes back: how can we reduce the development cost and duration, while improving the quality and the robustness of the products to satisfy consumers and governmental regulations. The stakes of this question are crucial and the entire industrial world is looking into it.

In the automotive industry, manufacturers are always looking for the answer because of the necessity to increase the complexity of systems to reach the new pollutant standards. For instance, in a few years, the classical Internal Combustion Engine (ICE) has indeed become a very complex system combining many high technological components. Nevertheless, with the introduction of drastic targets on $\mathrm{CO}_{2}$ emissions at $130 \mathrm{~g} / \mathrm{km}$ in 2012 and $95 \mathrm{~g} / \mathrm{km}$ in 2020 for light-duty vehicles, car manufacturers are facing to a veritable technological bottleneck because future ICE improvements will be probably not sufficient to reach these ambitious targets. Vehicle hybridization and electrification seem to be some costly but relevant approaches to combine all the constraints related to automotive industry and limit $\mathrm{CO}_{2}$ emissions. One of the main drawbacks of hybridization is the increasing complexity of the powertrains. The latter has to manage several energy sources (fuel and electrical energy storage systems) and several types of propulsion devices (ICE, Electric Motors) and benefit from these new degrees of freedom to operate with the most optimal way... In the world, a difficult problem to solve.

To help engineers, system simulation can offer an interesting potential to support the specification, the optimization and the management of such complex systems. Nowadays, everybody agrees that simulation is a helpful support for all the development stages of an innovative ICE. The increasing complexity of new powertrains makes system simulation indisputable, but necessitates a relevant modelling methodology for the different components in order to study and optimize the interactions within the complete system.

This paper presents a global methodology whose objective is to develop a predictive model of an Electric Motor (EM) and be able to integrate and use it in a complete vehicle simulator. To reach this objective, computing time of the final EM model has to be limited to guarantee the exhaustive use of the complete vehicle simulator at the different stages of the conception of a new concept. For instance, the complete vehicle simulator has to be compatible with real time capabilities to help the design and the validation of innovative control strategies.

The presented methodology is based on the use of several tools and models available to study electric components: Finite Element Models (FEM's), analytical models to characterize Electric Motor and finally simulation models in the rotor reference frame using Park transformation to simulate the behavior of the EM. These different tools deal with different compromises between modelling accuracy and computation durations. The paper presents the application of this methodology on a well-know Electric Motor technology: the Interior Magnet Synchronous Motor with V-shape magnet, (V-IPMSM), technology used in the Toyota Prius II vehicle. The final EM model is integrated in a complete vehicle simulator and evaluated on a driving cycle.

\section{GLOBAL METHODOLOGY PRESENTATION}

\subsection{The Context: System Simulation for Complete Vehicle}

To develop new but complex powertrains, system simulation is now become a crucial tool, able to reduce cost but also 


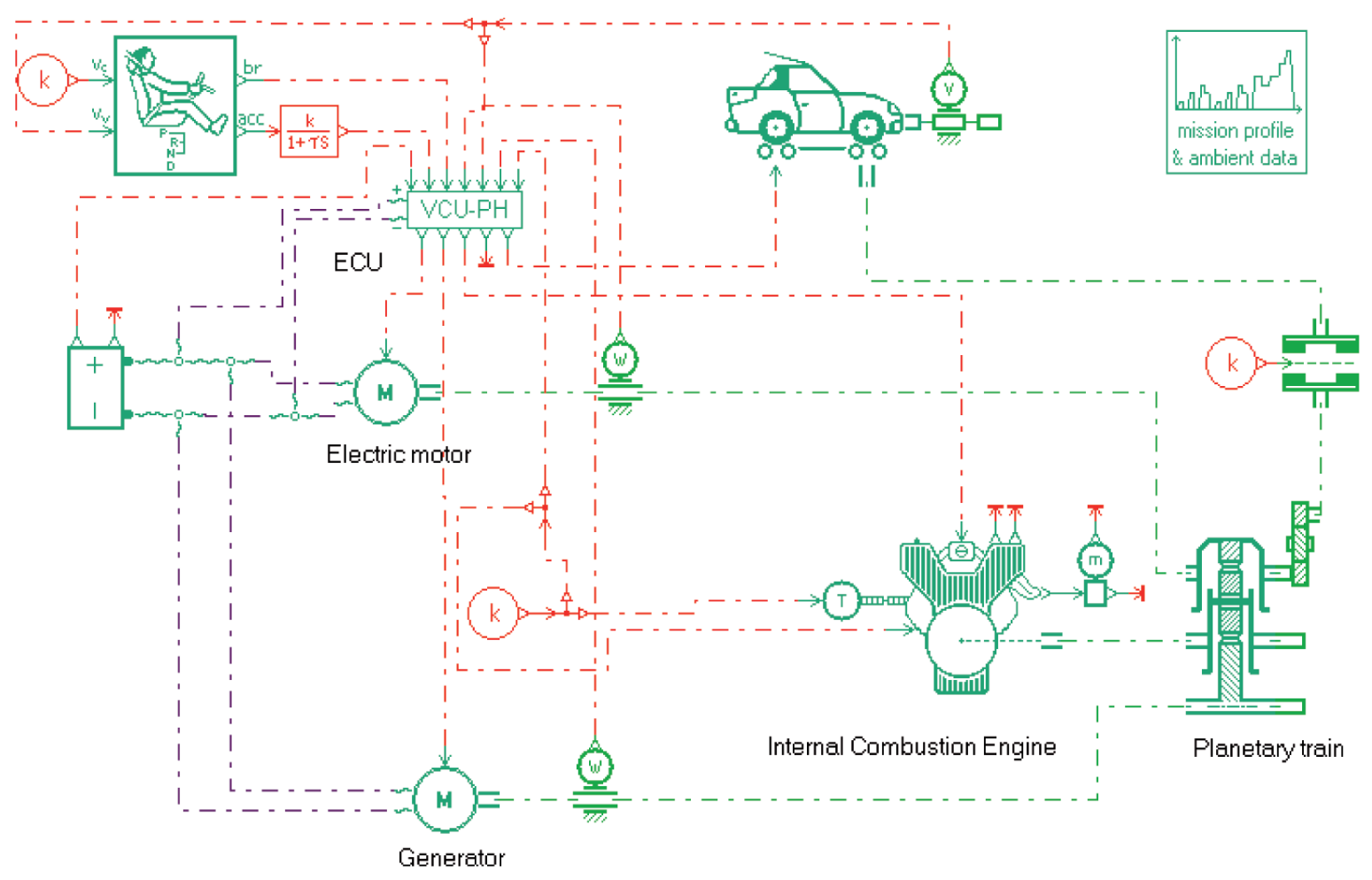

Figure 1

Example of a complete HEV simulator (powersplit architecture).

duration of design process. Many studies on new Hybrid Electrical Vehicle (HEV) concepts have been the opportunity to create a complete vehicle simulator, notably to understand the system and the component interactions [1], to help to specify the characteristics of the different components [2], to develop and validate control strategies [2]. An example of such a HEV simulator is presented in Figure 1.

To be integrated and used in a complete vehicle simulator, a model has to reach the following objectives:

- to be representative and accurate on the main physical phenomena occurring in the system;

- to be compatible with the CPU time constraints of the application;

- to be robust enough to be associated with other model of components and simulate interactions occurring in a complex system.

Most of the time, all of these objectives are difficult to reach at the same time. As far as the study of Electric Motor is concerned, several tools are available to model this specific component, with advantages and drawbacks. A way to associate and use the different tools in order to create relevant model compatible with system simulation is illustrated in the following part.

\subsection{The Available Tools to Study Electrical Motors and their Interactions: from FEM to Look-Up Table Models}

From a simple point of view, every model developed for simulation can be organized on a physical modelling level axis, from Finite Element Models (FEM's) to simple look-up table models (Fig. 2). This kind of diagram has been already illustrated for Internal Combustion Engine (ICE) modelling in [4]. FEM models are the most complex and the most accurate ones, but are also the most CPU expensive ones. They are the references and the methodology consists in reductions and simplifications to go from FEM models to simplest ones, analytical models for instance. This methodology reduces model complexity and optimizes CPU time performances. The main advantages of such a development process are the following ones:

- to take benefits from a coherent framework thanks to the up-level models which are used as modelling guidelines;

- to have an access to detailed variables from the most accurate models to facilitate the refined validation of new developments; 


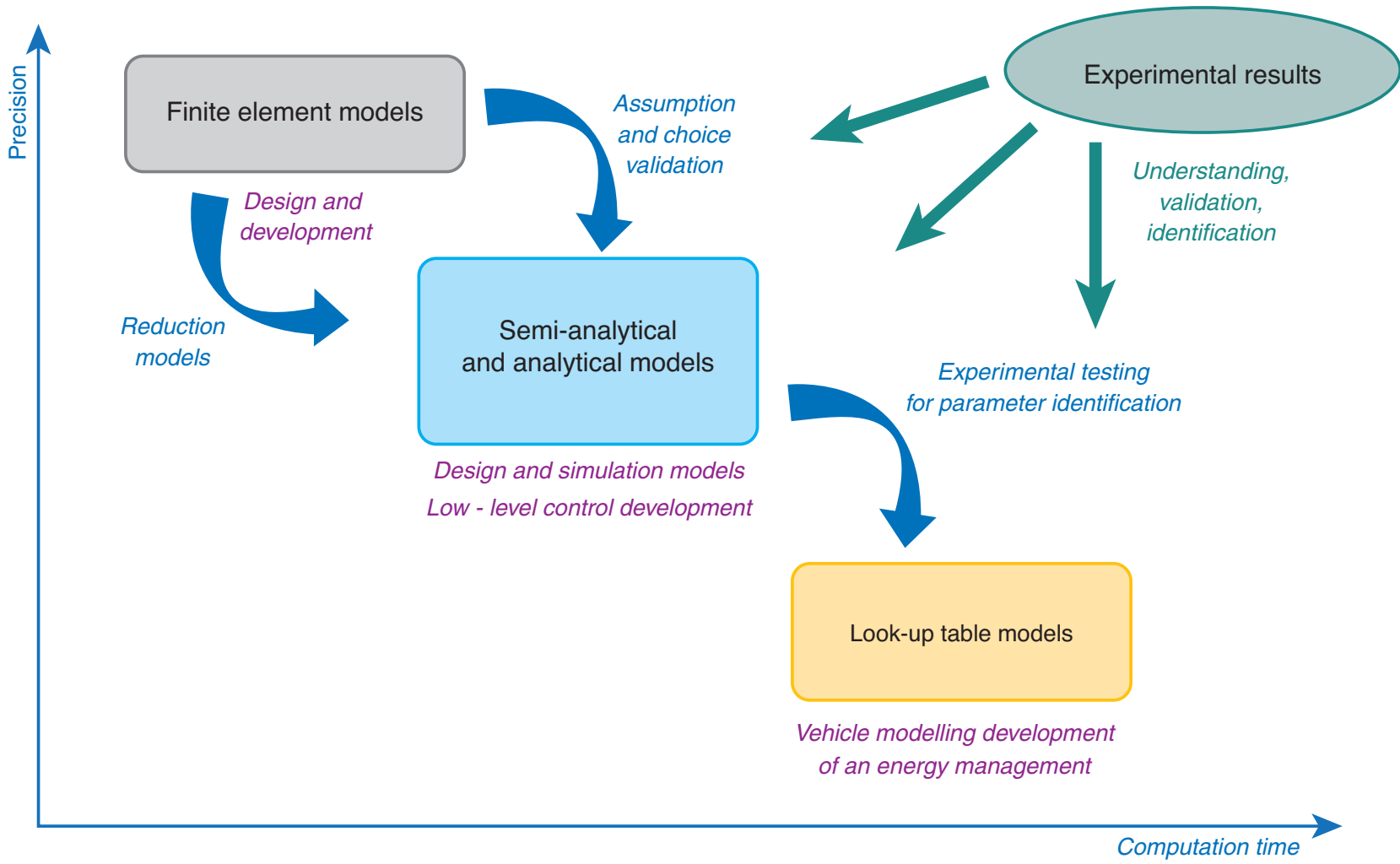

Figure 2

Simulator design and modelling levels invs. Computation time and precision.

- to offer an efficient validation tool which allows to obtain the reference results with more flexibility than with experimental test bed.

Experimental results are still required for a complete model design to understand phenomena, but also to identify and validate the different modelling levels.

The different types of model presented in the diagram in Figure 2 have been developed on a well-know Electric Motor technology: the V-IPMSM. The following sections presented this work and the associated validations.

The first section of this paper presents the development of an analytical approach in order to estimate the electromagnetic parameters of the V-IPMSM. This methodology has been validated by using FEM analysis and the experimental results.

The following section consists in the presentation of the V-IPMSM model in the well-known Park farm. An ideal control algorithm which allows the motor to be driven with Maximum Torque Per Ampere characteristic (MTPA) below the base speed has been integrated. This algorithm maintains also the maximum voltage limit of the motor under wide flux weakening and the motor current limit under all conditions of operation accurately. The steady state model of the motor takes also into account the differences losses of the motor, such as iron and copper losses. This steady state model is finally used to generate the efficiency map of the Electric Motor to be compared to the measured one.

Finally, in the last section, the steady state analytical model is embedded in the Toyota Prius II complete vehicle simulator. The latter is running on the New European Driving Cycle (NEDC) and some results of this simulation are given.

\section{ANALYTICAL CARACTERISATION OF V-IPMSM}

Figure 3 presents a picture of the EM rotor, structured with 8 poles. Each pole is constituted with two permanent magnets shaped on V. A cross section of one-half of the two magnets and the associated stator and rotor back iron behind the magnet halves is described in Figure 4. An equivalent magnetic circuit based on the geometrical structure of this description is used to estimate the main electro-magnetic parameters used afterwards in the simulation model. 


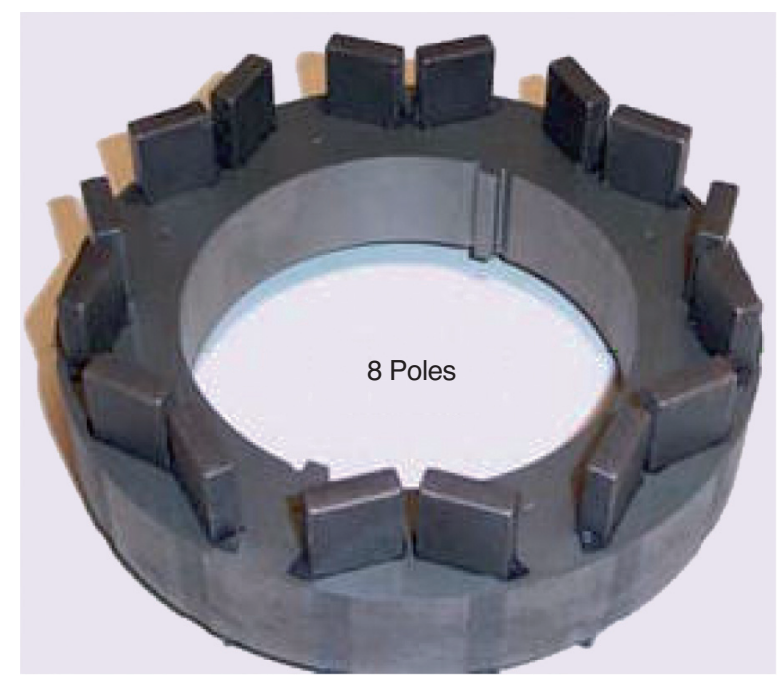

Figure 3

V-IPMSM motor rotor.

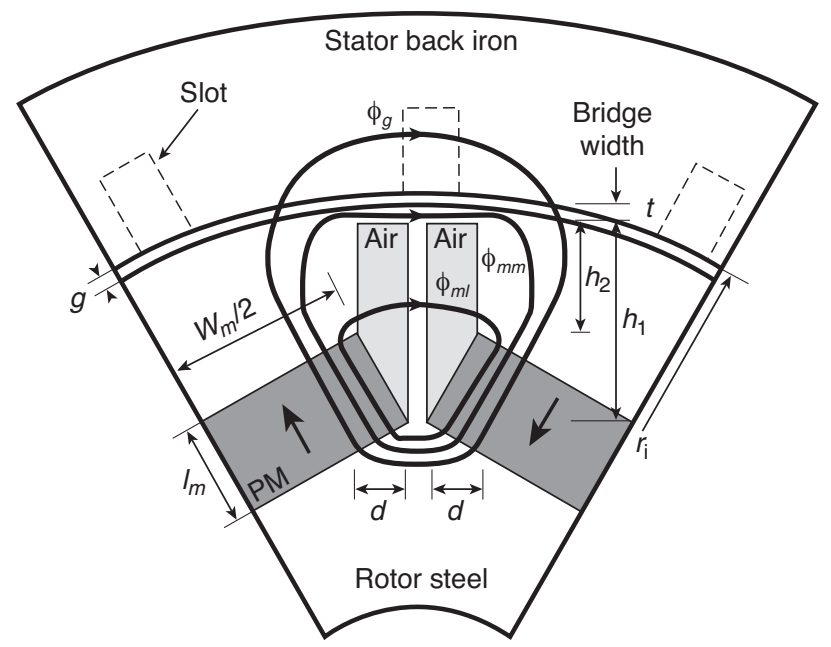

Figure 4

V-IPMSM motor structure.

\subsection{Description of the Analytical Model}

Based on the geometrical structure of the motor (Fig. 4), a detailed magnetic equivalent circuit of the motor is used to calculate the average air gap flux density:

$$
B_{g}=\frac{C_{\Phi}}{1+\beta(1+2 \eta+4 \lambda)} B_{r}
$$

where $B_{r}$ is the remanence of the magnet, $C_{\Phi}=A_{m} / A_{g}$ the flux concentration factor and $A_{g}$ and $A_{m}$ are the cross-sectional areas per pole of the air gap and magnet, respectively [6]. Magnetic reluctances of stator and rotor cores are not taken into account. The values of parameters in Equation (1) are given by:

$$
\begin{gathered}
\beta=\frac{\mu_{r e c} K_{c} g}{w_{m}} C_{\Phi} \\
\eta=\frac{w_{m}\left(h_{1}+h_{2}\right)}{4 d \mu_{r e c} l_{m}} \\
\lambda=\frac{1+1 / \beta+2 \eta}{2\left(A_{m} / A_{m m}\right)\left(B_{r} / B_{s}\right)-4}
\end{gathered}
$$

where $g$ is the air gap length, $K_{c}$ the carter coefficient, $\mu_{\text {rec }}$ the recoil permeability and $A_{m m}=t l$ represents the cross sectional area of the iron bridge above the nonmagnetic barriers with $t$ and $l$ being the bridge width and motor stack length, respectively. $l_{m}$ and $w_{m}$ denote the magnet length and width. $h_{1}$ and $h_{2}$ represent the inner and the outer flux barrier heights, respectively. $B_{s}$ is a limit of the leakage flux density in the bridge due to saturation. Using $B_{g}$ from Equation (1) in connection with Equations (2) and (4), the maximum value of PM flux linkage is obtained as [6]:

$$
\psi_{m}=\frac{4 D l}{\pi}\left(\frac{K_{W 1} N_{p h}}{p}\right) B_{g} \sin (\alpha)
$$

The $d$ - and $q$-axis inductances can be expressed as [6]:

$$
\begin{aligned}
& L_{d}=\frac{3 \mu_{0} D l}{\pi p^{2} g_{d}} k_{w 1}^{2} N_{p h}^{2}+L_{f} \\
& L_{q}=\frac{3 \mu_{0} D l}{\pi p^{2} g_{q}} k_{w 1}^{2} N_{p h}^{2}+L_{f}
\end{aligned}
$$

where $L_{f}$ is the per-phase leakage inductance [8] and:

$$
\begin{aligned}
& g_{d}=\frac{k_{c} g}{k_{1 a d}-\left(k_{1} k_{\alpha d} /(1+\beta(1+2 \eta+4 \lambda))\right)} \\
& g_{q}=\frac{k_{c} g}{k_{1 a d}}
\end{aligned}
$$

with:

$$
\begin{aligned}
& k_{1 a d}=\alpha+\frac{\sin \alpha \pi}{\pi}, \quad k_{1 a q}=\alpha+0.1+\frac{\sin 0.1 \pi-\sin \alpha \pi}{\pi}, \\
& k_{\alpha d}=\frac{\sin (\alpha \pi / 2)}{\alpha \pi / 2}
\end{aligned}
$$

\subsection{FEM Model}

To validate the analytical methodology to calculate the electro-magnetic parameters of the motor, a FE model is used on the described motor thanks to the Flux2D software [15]. 
2D FE analysis allows the accurate determination of the inductances through magnet flux distribution solutions as it takes into account the actual distribution of the armature winding, the details of cross section geometry and the nonlinearities of magnet materials.

\subsection{Analytical Model Comparison with FE Model and Experimental Results}

In order to validate the global methodology, the electromagnetic parameters of the Toyota Prius II Electric Motor are estimated thanks to the presented analytical approach and the FE model. The geometrical parameters of the Toyota EM are well described in litterature $[11,12]$. These electromagnetic parameters have also been identified with dedicated experimental tests and are compared in Table 1. The analytical predictions of the unsaturated parameters present a good agreement with those from FEA and measurement (relative error inferior to $10 \%$ ).

These results validate the global methodology to estimate analytically the electro-magnetic parameters. Nevertheless, improvements can be brought to the analytical model, thanks to the use of FE model, notably to takes into account saturation effects.

TABLE 1

Electro-magnetic parameters results comparison

\begin{tabular}{c|c|c|c}
\hline & Analytical model & FE model & Experimental tests \\
\hline$\psi_{m d}(\mathrm{~Wb})$ & 0.185 & 0.198 & - \\
\hline$L_{d}(\mathrm{mH})$ & 1.900 & 2.000 & 2.10 \\
\hline$L_{q}(\mathrm{mH})$ & 4.900 & 5.200 & 5.00 \\
\hline
\end{tabular}

\subsection{Analytical Model Improvements Thanks to FE Model Results}

As shown in the previous part, FE model is used as a reference tool for validation. FE model offers also the capability to give more information on complex phenomena difficult to model with analytical model. For instance, saturation effects can be taken into account in the presented analytical model by introducing the variation of the saturated $d$ - and $q$-axis inductances with the armature- stator current. These results, given by FE simulations, are shown in Figure 5.

The improvement brought by the introduction of the saturation effects will be illustrated by other publications. This more accurate estimation of the electro-magnetic parameters in the $d / q$ axis reference frame, the simulation model can be set. The next sections will present the different hypotheses and equations implemented in this model.

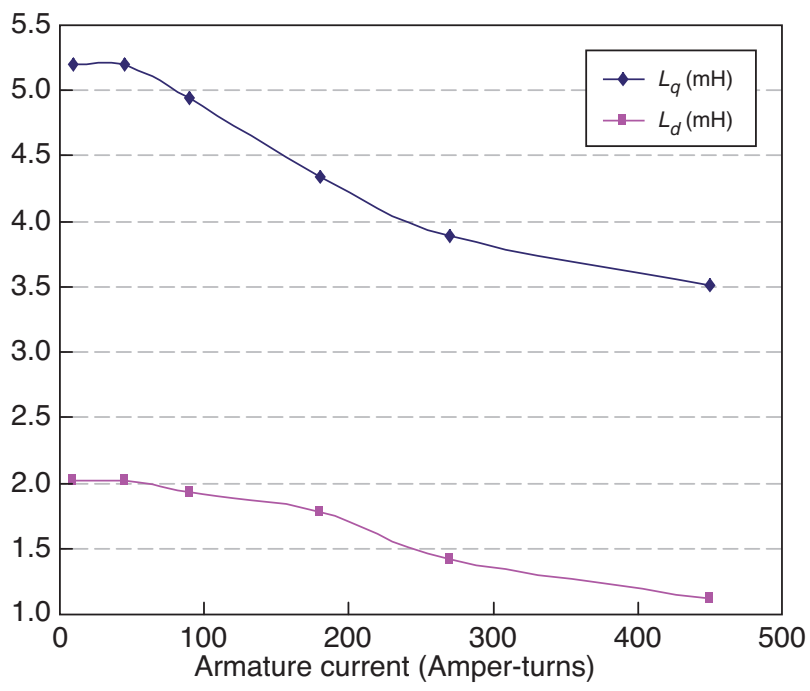

Figure 5

Variation of $d$ - and $q$ - axis inductances with armature - stator current.

\section{SIMULATION MODEL OF THE V-IPMSM}

The simulation model is generally divided into different parts:

- the electric equations in the $d / q$ axis reference frame;

- a quasi-static control strategy to determine $d$ - $q$ axis currents;

- the equations to model the different losses occurring in the EM.

These aspects are illustrated in the following sections.

\subsection{Equations for Electric Model}

A conventional steady state $d-q$ electrical hypothesis in a synchronously rotating reference frame is used to model the behaviour of the IPMSM. The flux distribution in the air gap is assumed to be sinusoidal in this modelling approach. The torque provided by the motor is calculated as:

$$
T=p\left(\varphi_{r d} i_{q}+\left(L_{d}-L_{q}\right) i_{d} i_{q}\right)
$$

where $i_{d}$ and $i_{q}$ are the $d$ - and $q$-axis current components, $L_{d}$ and $L_{q}$ are the $d$ - and $q$-axis inductances, $\varphi_{r d}$ is the $d$-axis maximum flux linkage of permanent magnet, $p$ is the number of pole pairs and $T$ is the torque.

When a V-IPMSM synchronous motor is fed from an inverter, the maximum stator current and voltage are limited 
by the inverter/motor current and dc-link voltage ratings respectively. These constraints can be expressed as:

$$
\begin{gathered}
I_{s}=\sqrt{i_{d}^{2}+i_{q}^{2}} \leq I_{s m} \\
V_{s}=\sqrt{v_{d}^{2}+v_{q}^{2}} \leq V_{s m}=\sqrt{\frac{3}{2}} \frac{U_{d c}}{2}
\end{gathered}
$$

where $I_{s m}, V_{s m}$ are the available maximum current and voltage of the inverter/motor and $U_{d c}$ is DC link voltage.

\subsection{Control Strategy Description}

In order to satisfy current and voltage limits, the stator current vector must lie inside the current limit circle and voltage limit ellipse in all operating conditions as shown in Figure 6. Therefore, the control trajectories under the vector control are dictated by these limits. For any operating point, in the case where the stator current vector lies inside the current limit circle and voltage limit ellipse, the Maximum Torque Per Ampere (MTPA) control algorithm is applied to the IPM machine. However, when the terminal voltage reaches its limit value, the flux-weakening control is selected in order to satisfy both current and voltage limits. The transition between the MTPA and flux-weakening control is determined by the flow chart given in Figure 7.

\subsection{Loss Modelling}

Generally, 3 types of losses are generally taken into account in a model: iron losses, copper losses and mechanical losses. Mechanical losses are ignored in the presented model.

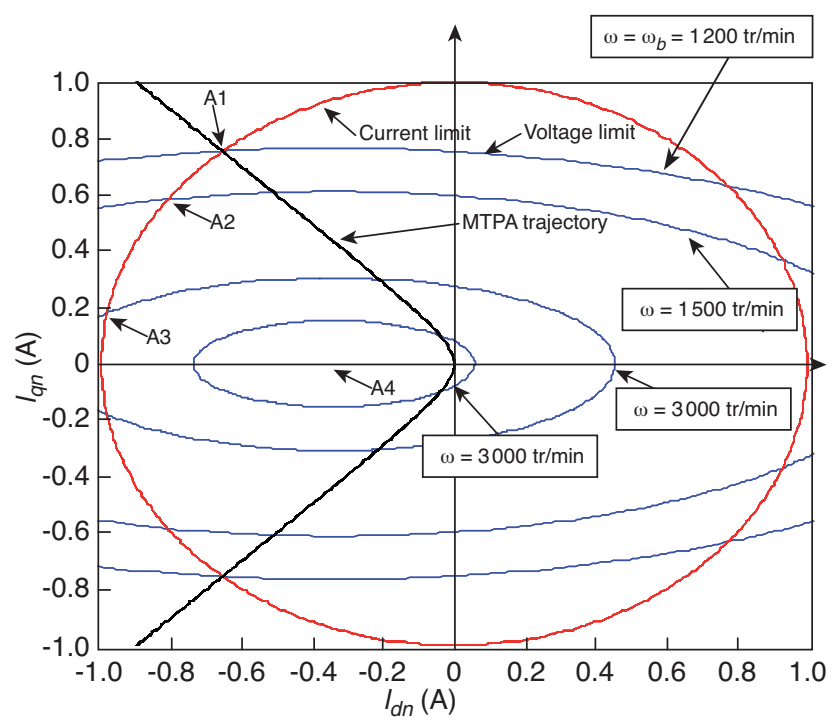

Figure 6

Control trajectories in $i_{d}-i_{q}$ plane.

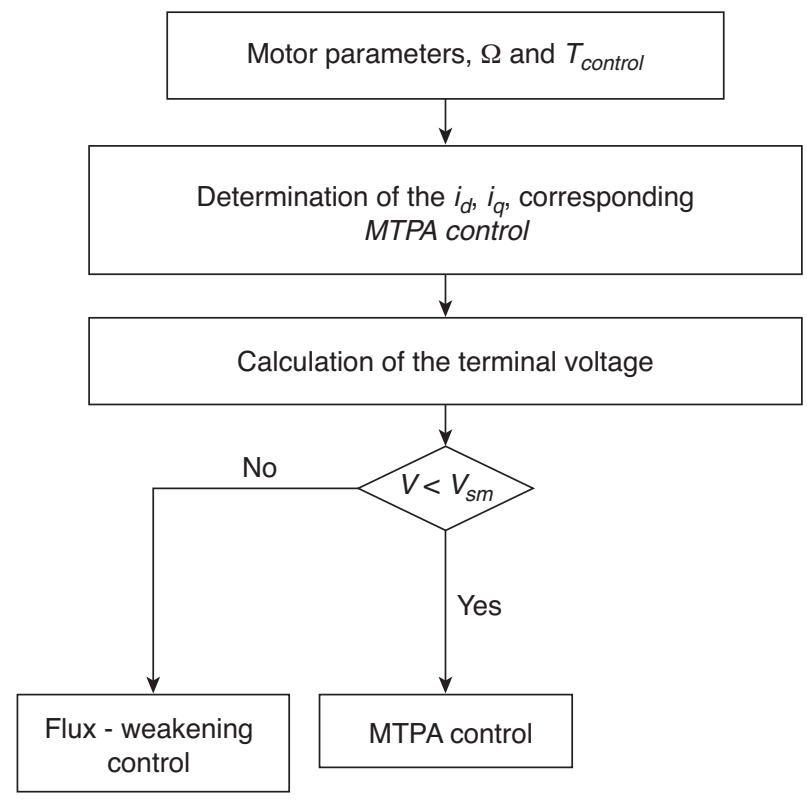

Figure 7

Flow chart of control mode transition.

Model of iron losses takes into account hysteresis, eddycurrent and excess losses. The equations used for this approach are well described in [14].

The copper losses in the stator wind can be classically expressed as:

$$
P_{j}=R_{s}\left(i_{d}^{2}+i_{q}^{2}\right)
$$

\subsection{Final Model Validation and Comparison with Experimental Results}

To finally validate the methodology, the simulation model described in the previous section is used to generate an efficiency map of Toyota Prius II Electric Motor. This map is represented in the rotation speed and torque shaft reference frame. This simulated efficiency map, presented in Figure 8, is compared to the measured one, illustrated in Figure 9 [11]. Distribution of efficiency zones is quite similar on these two maps. To perform a quantitative comparison, a relative error efficiency map (between simulation and experiment) is generated on the same operating points (see Fig. 10). It shows that the maximum error is $32 \%$ and the mean relative error is less than $7.5 \%$. The high level of error is obtained for high torque operating mode, where saturation phenomena generally occur. As explained before, these saturation effects are not taken into account in the model for the moment. However, improvement brought by the introduction of the 


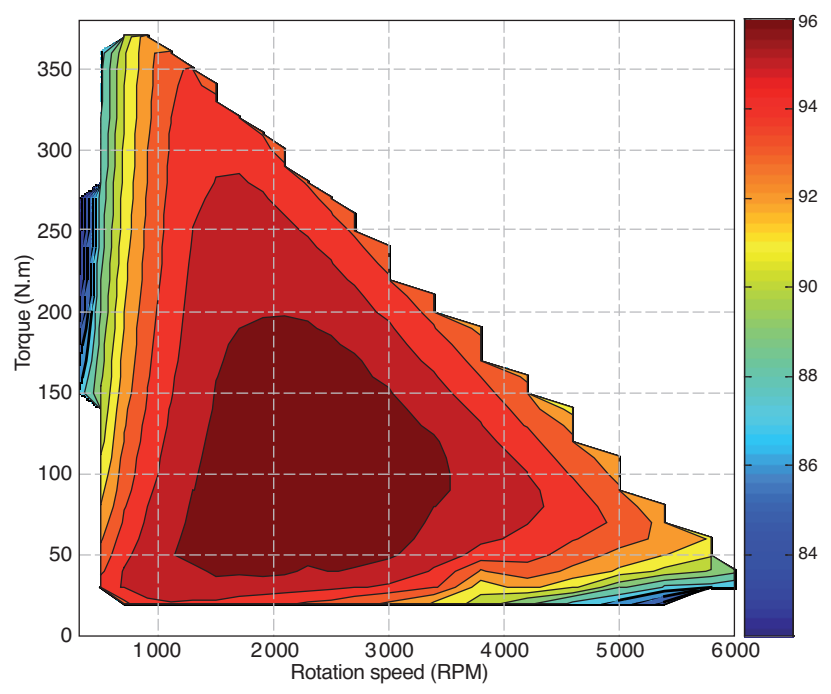

Figure 8

Simulated efficiency map.

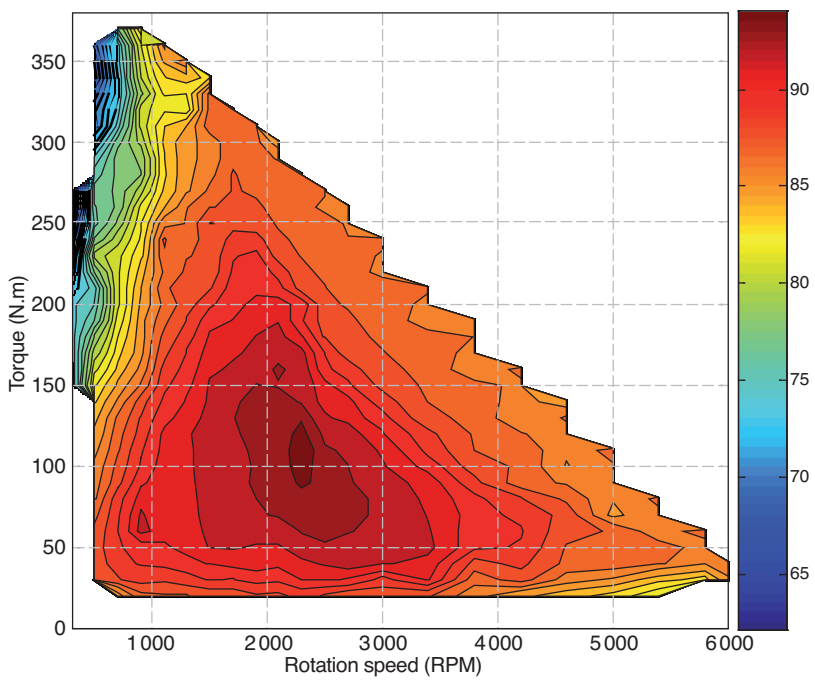

Figure 9

Experimental efficiency map.

saturation effects (see Sect. 2.4) will be illustrated by other publications.

$$
\eta(\%)=\left(\frac{C_{e m} \Omega}{C_{e m} \Omega+P_{j}+P_{f e r}}\right)^{\operatorname{sign}(\mathrm{Cem})} \times 100
$$

The previous results show that the simulation model can be considered as validated. This model can be integrated in a complete HEV simulator to evaluate its behaviour on vehicle driving cycles.

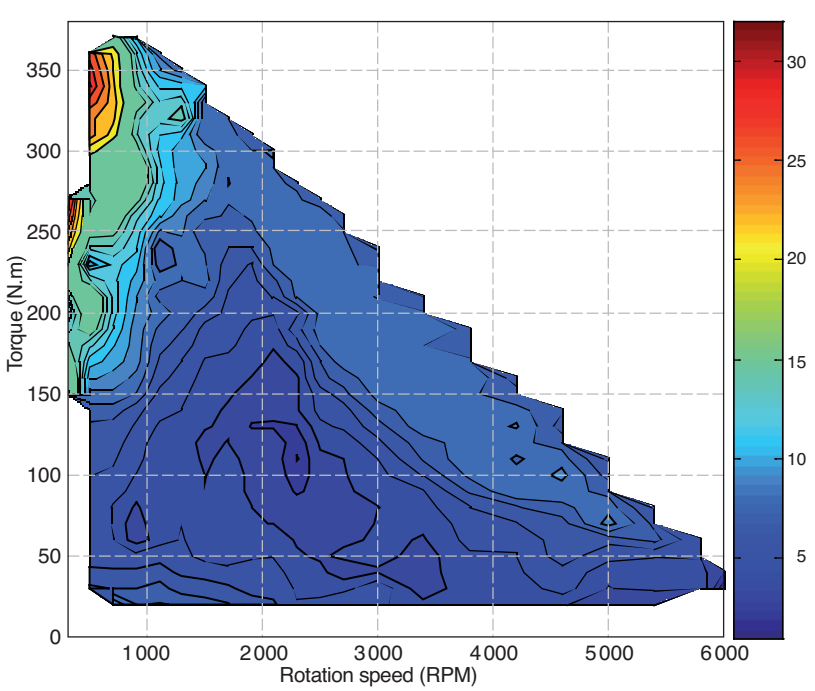

Figure 10

Comparison between simulated and experimental efficiency maps.

\section{MODEL INTEGRATION IN THE COMPLETE VEHICLE SIMULATOR}

\subsection{Simulator Presentation}

The Toyota Prius II vehicle simulator (see Fig. 11) was developed during a previous study [13]. In this simulator, Electric Motors and power electronics devices are simply modelled using maps of energy losses and efficiency. The simulator is running using the co-simulation techniques between LMS.IMAGINE.Lab AMESim ${ }^{\circledR}$ and Simulink ${ }^{\circledR}$. LMS.IMAGINE.Lab AMESim ${ }^{\circledR}$ offers an intuitive and convenient physical modelling environment and a large number of pre-built libraries to simulate the vehicle powertrain and drive components. Simulink ${ }^{\circledR}$ is used to implement the control energy management algorithm.

\subsection{Methodology Used to Integrate the Analytical Models of the Prius II Motor and its Inverter}

The model described in the previous section has been integrated in a Toyota Prius II vehicle simulator (see methodology in Figure 12 and global vehicle simulator in Figure 11. The motor rotation speed and the motor voltage are input variables. The motor electromagnetic torque and motor current are the output variables. The Electric Motor receives the target torque from a global energy management. This one is used to define current components in $d-q$ axis (see Fig. 7). 


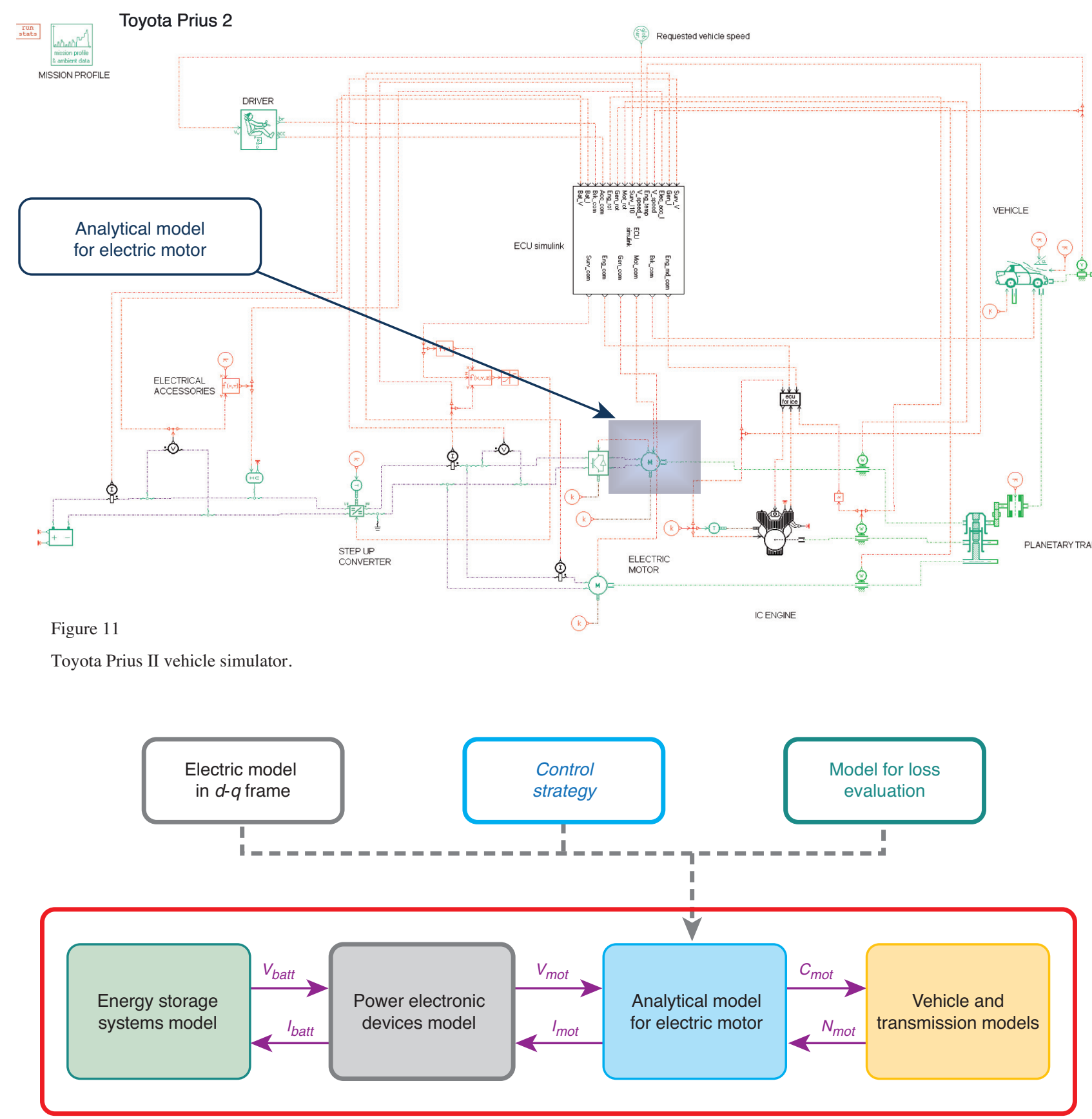

System simulator

Figure 12

Methodology used to integrate the analytical Prius II motor in complete vehicle.

\subsection{Results on Driving Cycle}

The Toyota Prius II simulator with the analytical model is then evaluated on a New European Driving Cycle (NEDC) driving cycle. A comparison is made on the simulation results obtained by the reference simulator (with maps) and this new one.
As shown in Figure 13, the vehicle simulator follows correctly the target speed of the NEDC. Figure 14 shows that target EM torque is also correctly by the analytical model. Figure 15 illustrates the power spit between the Internal Combustion Engine (ICE) and the EM thanks to the energy management supervisor. With all these comparisons, it can 


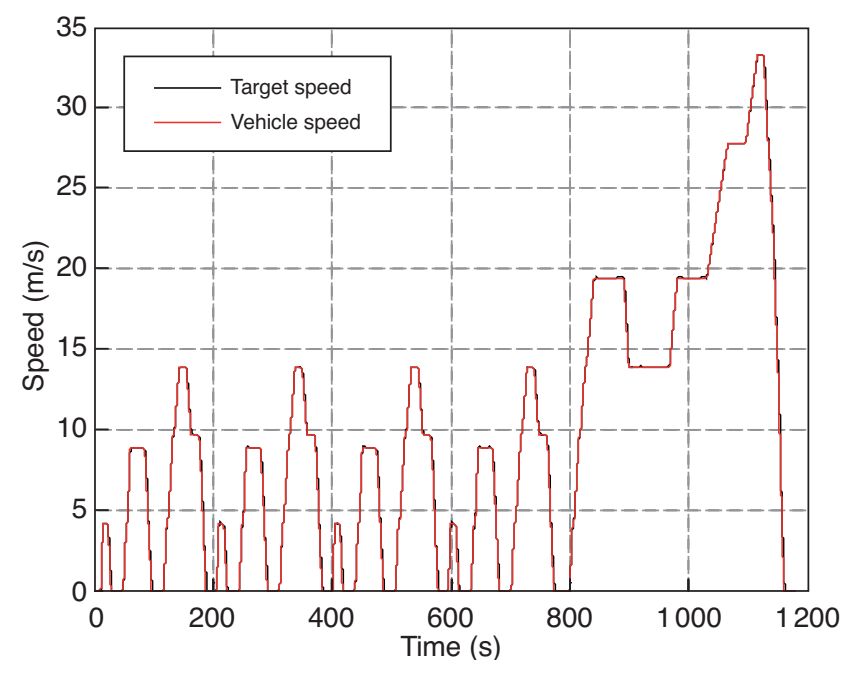

Figure 13

Target and real vehicle speed during the NEDC.

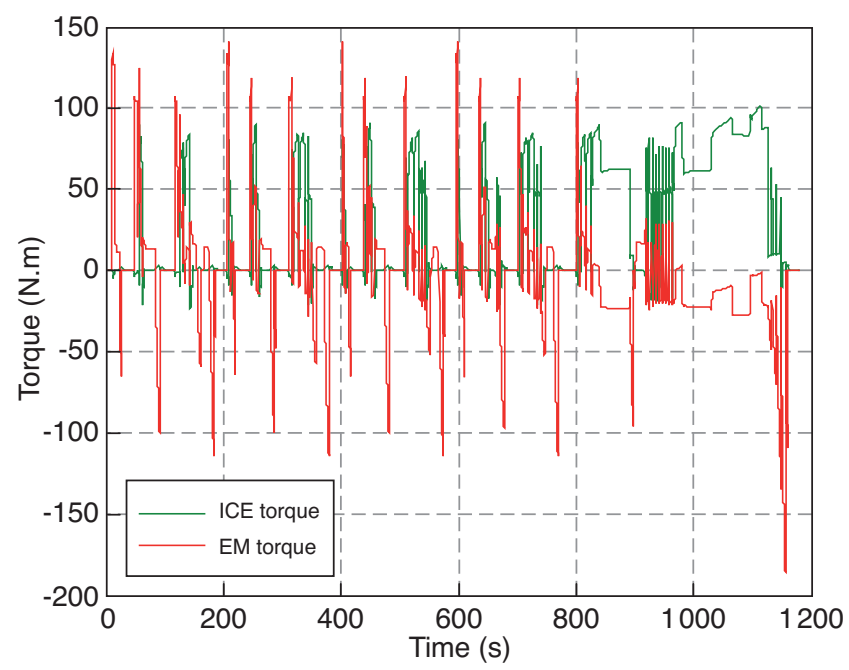

Figure 15

ICE end EM torque during the NEDC.

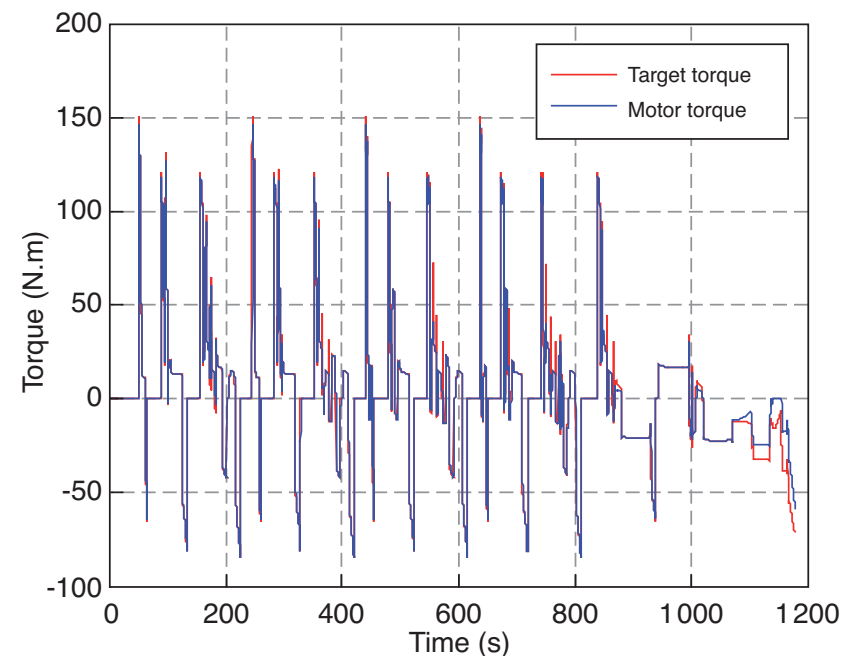

Figure 14

Target and real EM torque during the NEDC with the reference simulator.

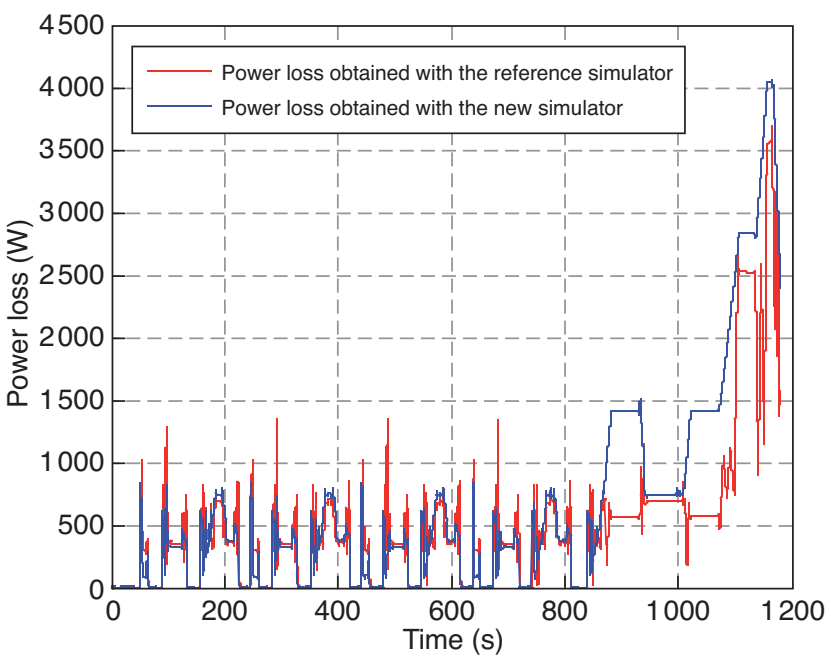

Figure 16

Losses in the EM during the NEDC. be concluded that the analytical model is well integrated in the complete simulation.

Figure 16 compares the global losses evaluated by the mapping model and the analytical models. Some differences appear during the high speed phases. These differences are probably due to the evaluation of EM losses that are clearly different between the map model and the analytical model and impact the evolution of battery state of charge (Fig. 17).

However, Figure 18 shows the different losses in the EM during the NEDC.
Table 2 summarizes the simulation duration (in second) on the NEDC of each vehicle simulator. The simulation time of the new simulator is more than two times higher than the previous one of the reference simulator. It can be noticed that no work has been done to optimize the analytical model CPU time. It could be interesting to keep on working on this aspect to limit the CPU time cost of this improved electrical model. Nevertheless, the new simulator has some very interesting advantages. With a more accurate evaluation of the iron losses, it is better adapted to develop advanced control 


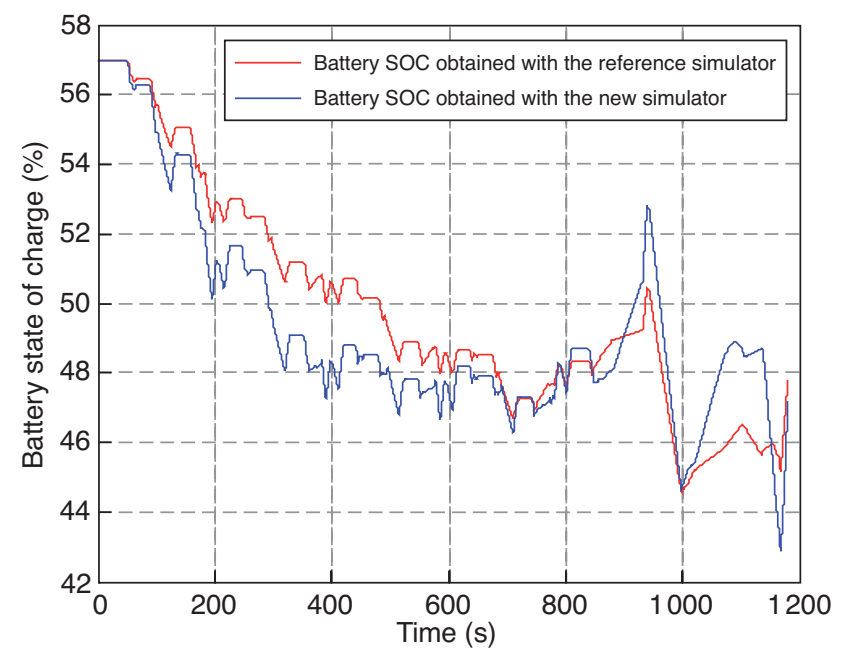

Figure 17

Battery state of charge during the NEDC.

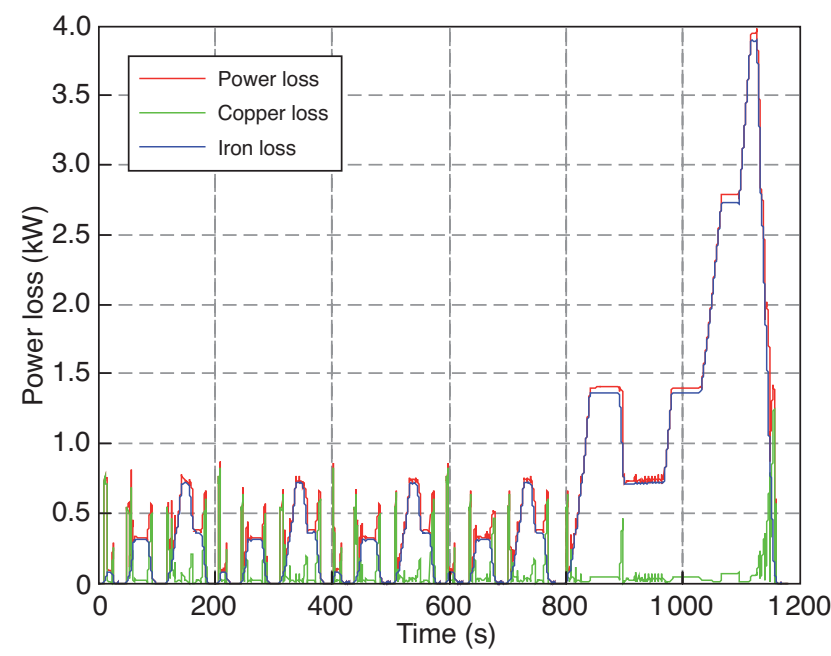

Figure 18

Losses in the EM during the NEDC. strategies. It allows also calculating the different types of Electric Motor internal losses and predicting them in the different parts of motor. This could be an interesting advantage to model accurately the thermal behavior of the motor.

TABLE 2

Simulation time during NEDC

\begin{tabular}{c|c|c}
\hline & Reference simulator & New simulator \\
\hline CPU time (s) & 114 & 287 \\
\hline
\end{tabular}

\section{CONCLUSION}

The aim of this paper has been to illustrate a methodology allowing the design and the modelling of Electric Motor for vehicle simulator. To reach this objective, an analytical model to characterize the Prius II motor parameters has been presented. This analytical model has been validated by results obtained by a FE model and experimental measurements.

Based on the $d-q$ axis reference frame, a steady state simulation model with an ideal control algorithm has been also presented. The validation of this model has been done by comparing the measured efficiency map of the Toyota Prius II motor with the simulated one. The comparison shows a good agreement between the two maps, which guarantees a correct behavior of the model on the whole operating conditions of the motor. Finally, this model is integrated successfully in the complete vehicle simulator of the Toyota Prius II.

Further improvements on the model have been proposed to obtain a better behaviour and accuracy. A first improvement will consist in taking into account the saturation effects. A second one will probably focus on the improvement of the iron loss model, notably by taking into account the stator armature reaction effect. These two points will be illustrated with further publications.

\section{ACKNOWLEDGMENTS}

We would like to acknowledge J.C. Dabadie and G. Mauviot for their technical contributions.

\section{REFERENCES}

1 Sciaretta A., Dabadie J.C., Albrecht A. (2008) Control-Oriented Modeling of Power Split Devices in Combined Hybrid-Electric Vehicles, SAE paper 2008-01-1313.

2 Husain I., Islam M.S. (1999) Design, Modeling and Simulation of an Electric Vehicle System, SAE paper 1999-01-1149.

3 Verdonck N., Chasse A., Pognant-Gros P., Sciarretta A. (2010) Automated Model Generation for Hybrid Vehicles Optimization and Control, Oil Gas Sci. Technol. - Rev. IFP 65, 1, 115-132.

4 Rousseau G., Sinoquet D., Sciarretta A., Milhau Y. (2008) Design optimization and optimal control for hybrid vehicles, EngOpt 2008 - International Conference on Engineering Optimization, Rio de Janeiro, Brazil.

5 Albrecht A., Grondin O., Le Berr F., Le Solliec G. (2007) Towards a stronger simulation support for engine control design: a methodological point of view, Oil Gas Sci. Technol.-Rev. IFP $\mathbf{6 2}, 4,437-456$.

6 Paganelli G., Guerra T.-M., Delprat S., Santin J.-J., Delhom M., Combes E. (2000) Simulation and assessment of power control strategies for a parallel hybrid car, Proc. IMechE Part D: J. Automobile Engineering 214, 7, 705-718. 
7 Hwang C.C., Chang S.M., Pan C.T., Chang T.Y. (2002) Estimation of parameters of interior permanent magnet synchronous motors, J. Magn. Magn. Mater. 239, 1-3, 600-603.

8 Miller T.J.E. (1989) Brushless Permanent-Magnet and Reluctance Motor Drives, Clarendon Press, Oxford.

9 Arjona M.A., Macdonald D.C. (1999) A new lumped steadystate synchronous machine model derived from finite element analysis, IEEE Trans. Energy Convers. 14, 1, 1-7.

10 Engelmann R.H., Minddendrof W.H. (1995) Handbook of electric motors, Marcel Dekker, New York.

11 Staunton R.H., Ayers C.W., Marlino L.D., Chiasson J.N. (2006) Evaluation of 2004 Toyota Prius Hybrid Electric Drive System, ORNL/TM-2004/137, UT-Battelle, LLC, Oak Ridge National Laboratory, Oak Ridge, Tennessee.
12 Burress T.A., Coomer C.L. Campbell S.L. ,Seiber L.E., Marlino L.D., Staunton R.H., Cunningham J.P. (2008) Evaluation of the 2007 Toyota Camry hybrid synergy drive system, UT-Battelle, LLC, Oak Ridge National Laboratory, Oak Ridge, Tennessee.

13 Vinot E., Scordia J., Trigui R., Jeanneret B., Badin F. (2008) Model simulation, validation and case study of the 2004 THS of Toyota Prius, Int. J. Vehicle Systems Modelling Testing 3, 3, 139-167.

14 Roshen W. (2007) Iron Loss Model for permanent - Magnet synchronous Motors, IEEE Trans. Magn. 43, 8, 3428-3434.

15 Flux2D (Version 10.3) (2009) Tutorial: Brushless permanent magnet motor. CEDRAT.

Final manuscript received in June 2011 Published online in November 2011

Copyright (C) 2011 IFP Energies nouvelles

Permission to make digital or hard copies of part or all of this work for personal or classroom use is granted without fee provided that copies are not made or distributed for profit or commercial advantage and that copies bear this notice and the full citation on the first page. Copyrights for components of this work owned by others than IFP Energies nouvelles must be honored. Abstracting with credit is permitted. To copy otherwise, to republish, to post on servers, or to redistribute to lists, requires prior specific permission and/or a fee: Request permission from Information Mission, IFP Energies nouvelles, fax. +33147527096 , or revueogst@ifpen.fr. 